\title{
Does Advertising Content Matter? Impacts of Healthy Eating and Anti-Obesity Advertising on Willingness to Pay by Consumer Body Mass Index
}

\author{
Ruitong Wang, Jura Liaukonyte, and Harry M. Kaiser
}

\begin{abstract}
This study examines the impacts of two types of advertising content-healthy eating and anti-obesity advertising-on the demand for healthy and unhealthy food and beverage items. We show that differentiating consumers by weight is crucial in fully understanding the effects of advertising content on food and beverage demand. We find that among overweight individuals, anti-obesity advertisements are more effective than healthy eating advertisements at reducing the demand for unhealthy items and increasing the demand for healthy items. Furthermore, the magnitude of this effect increases with BMI. We discuss possible explanations and policy implications based on our results.
\end{abstract}

Key Words: advertising content, anti-obesity advertising, experimental economics, healthy eating advertising

\section{Introduction}

Obesity is a systemic health problem in the United States. In 2012, 40 percent of the US population was classified as overweight, and 75 percent as overweight or obese (Flegal et al. 2012; Hellmich 2013). Medical research reveals that obesity (and/or being overweight) is linked to significant health problems including diabetes, heart disease, and certain types of cancer (Andreyeva, Sturm, and Ringel 2004) and this adds to nation's overall health care costs. For instance, Cawley and Meyerhoefer (2012) estimate that obesity-related health problems raise the U.S. annual medical cost per person by $\$ 2,741$ (in 2005 dollars), or by $\$ 860.4$ billion annually overall. However, Bhattacharya and

Ruitong Wang Graduate Student, Jura Liaukonyte Dake Family Assistant Professor and Harry M. Kaiser Gellert Family Professor, Charles H. Dyson School of Applied Economics and Management Cornell University Correspondence: Jura Liaukonyte - Charles H. Dyson School of Applied Economics and Management -Cornell University • Ithaca - NY 14853340 Warren Hall • Phone 607.255.6328• Email Jurate@cornell.edu

Senior authorship is shared equally among the three authors. The views expressed are the authors' and do not necessarily represent the policies or views of any sponsoring agencies. This material is based upon work that is supported by the National Institute of Food and Agriculture, U.S. Department of Agriculture, Hatch under 1003974.

Agricultural and Resource Economics Review 47/1 (April 2018) 1-31

(C) The Author(s) 2018. This is an Open Access article, distributed under the terms of the Creative

Commons Attribution licence (http://creativecommons.org/licenses/by/4.0/), which permits unrestricted re-use, distribution, and reproduction in any medium, provided the original work is 
Sood (2011) argue that while obesity-induced health care costs are high, they are mainly paid for by obese people and do not generate enough negative externalities to justify a Pigouvian case for public intervention.

There is no doubt that consuming too much food-particularly unhealthy food-contributes to obesity. Therefore, changing people's eating habits is essential to decreasing the obesity rate. Health experts have paid increasing attention to implementing various policies aimed at either encouraging healthy eating behavior or discouraging unhealthy eating behavior, and a number of studies have evaluated the efficacy of these policies. They include imposing so-called "fat taxes" on foods high in sodium, fat, and added sugar and including so-called "thin subsidies" on vegetables and fruits (e.g., Kuchler, Tegene, and Harris 2005; Chouinard et al. 2007; Powell and Chaloupka 2009; Andreyeva, Chaloupka and Brownell 2011; Edwards 2011; Streletskaya et al. 2013) as well as making the calorie content of certain foods more apparent through labeling (Harnack et al. 2008; Downs, Lowenstein, and Wisdom 2009; Dumanovsky et al. 2011, Schwartz et al. 2012; Amatyakul 2013; Ellison, Lusk, and Davis 2014a, b). Conclusions on the efficacy of such policies are mixed. Although "fat taxes" have been shown experimentally to have modest effects (e.g., Epstein et al. 2010; Andreyeva, Chaloupka and Brownell 2011; Streletskaya et al. 2013), other researchers (e.g., Kuchler, Tegene, and Harris 2005; Chouinard et al. 2007), using secondary data, have found them to be only marginally effective, given the highly inelastic demand for food in the United States. With respect to calorie-content labeling, several studies have reported moderate changes in purchasing choices (Bassett et al. 2008; Chu et al. 2009) or eating behaviors (Burton et al. 2006; Roberto et al. 2010; Amatyakul 2013), while others have found such labeling to have minimal or no effect (e.g., Downs, Lowenstein, and Wisdom 2009; Ebel et al. 2009; Finkelstein et al. 2011; Ellison, Lusk, and Davis 2014a).

Liu et al. (2014) argue that most anti-obesity policies are based on the assumption that people act rationally when making food choices, which implies that people make poor food choices due to a lack of either appropriate monetary incentives or imperfect information. There is strong evidence, however, to suggest that people often behave irrationally when making food-related choices (Wansink 2006; Loewenstein, Downs, and Wisdom 2009). Thus, to improve the effectiveness of anti-obesity policies, Galizzi (2014) and Liu et al. (2014) suggest combining conventional economic interventions to impact rational choices with behavioral policies designed to affect individuals subconsciously.

The two major types of advertising designed to encourage healthy food choices and/or to discourage unhealthy food choices are "healthy eating advertisements" and "anti-obesity advertisements." Healthy eating advertisements are designed to encourage consumption of foods such as fruits and vegetables and are mainly sponsored by fruit and vegetable marketing boards or by state governments. Compared with the enormous amount of money spent on unhealthy food 
advertisements, the expenditure on healthy food advertising is negligible ${ }^{1}$. For instance, Chapman, Nicholas, and Supramaniam (2006) report that 80 percent of the food advertisements in Australia promote the consumption of unhealthy food, even though recent studies on healthy eating advertising (e.g., Rickard et al. 2011; Liaukonyte et al. 2012; Streletskaya et al. 2013; Rusmevichientong et al. 2014) have indicated that healthy eating advertising has a statistically significant and positive effect on increasing the consumption of fruit and vegetables. In their field experiment, Pollard et al. (2008) found that the "Go for 2\&5" campaign in Western Australia increased the average number of fruit and vegetable servings consumed by 20 percent (from 4.2 to 5 servings) over a three-year period (2002-2005).

Anti-obesity advertisements target primarily overweight or obese people and often contain frightening messages to persuade these individuals to reduce unhealthy food consumption. This type of advertising is mainly state sponsored and controversial due to its aggressive and negative nature. For example, the "Stop Childhood Obesity: Why am I Fat?" campaign, sponsored by Children's Healthcare of Atlanta, sparked a heated debate in Georgia with critics arguing that anti-obesity advertising can stigmatize overweight people, potentially causing them to engage in even unhealthier eating habits rather than healthier ones (Keneally 2012). Several psychologists (e.g., Brown, 2001; Ruiter, Abraham, and Kock, 2001; Brown and Locker, 2009) have also cast doubt on the efficacy of anti-obesity advertising because the negative nature of such advertising might have the unintended consequence of inducing resistance towards behavioral change. However, these behavioral studies lack the empirical evidence to support these hypotheses ${ }^{2}$.

Two recent experimental studies have attempted to measure the efficacy of healthy food and anti-obesity advertising. Streletskaya et al. (2013) found that healthy eating and anti-obesity advertising, in combination with policies such as an unhealthy food tax or a healthy food subsidy, reduce the calories, fat, and cholesterol in meal selection. Rusmevichientong et al. (2014) found that healthy eating advertising has a stronger impact than anti-obesity advertising on reshaping consumers' eating behavior. However, a major limitation of these studies was that they treated consumers as a homogenous group and did not differentiate the advertisements' impacts by consumer body weight. Researchers have shown that overweight individuals are more

\footnotetext{
1 One explanation for the large investment in unhealthy vs. healthy food advertising is that healthy foods tend to be commodities such as fruits and vegetables, and therefore there is less incentive for individual producers to advertise because it is difficult to differentiate commodities. Instead, the majority of commodity marketing efforts go through marketing boards or state governments. Unhealthy food products, on the other hand, are often heavily branded by private companies looking to grow their market share in a highly competitive space. Hence, there is much more money spent on advertising these products.

2 The exception is Schvey et al. (2011), who find that, among overweight women, exposure to weight-related stigmatizing material may lead to an increase in calorie consumption.
} 
likely to be present-biased, which is to say they value immediate gratification over long-term benefit (O'Donoghue and Rabin 1999; Komlos, Smith, and Bogin 2004; Borghan and Golsteyn 2006; Fudenberg and Levine 2006; McClure et al. 2007; Ikeda, Kang, and Ohtake 2010; Zhang and Rashad 2008). Relatedly, it has also been shown that overweight individuals have less selfcontrol (Fan and Jin 2014). Therefore, it is reasonable to conjecture that overweight individuals might have different reactions to advertising content relative to individuals of normal weight. Furthermore, the content of a certain advertising campaign might vary based on the intended target group or groups, which means that studying its impact for an entire population might produce biased results. For example, advertising directed at overweight individuals might be designed to have a drastic effect on the current eating behavior of those individuals, but it might not have any impact on individuals of normal weight. As we show in this paper, differentiation by weight is crucial to fully understanding the effects of healthy eating and anti-obesity advertising as well as to being able to design and implement advertising strategies with maximum effect.

Accordingly, the overall purpose of this study is to examine the impacts of healthy food and anti-obesity advertising on the demand for healthy and unhealthy foods and to determine how those impacts vary by consumer body mass index (BMI). To answer these questions, we conducted an economic experiment with 183 adult (non-student) subjects, each of whom was given the opportunity to purchase a variety of healthy and unhealthy snack food items, and were randomly placed into one of three groups: a control group, a healthy eating advertising treatment group, or an anti-obesity advertising treatment group. In all three cases, the subjects' willingness to pay (WTP) for each item was elicited twice: once at the beginning of the experiment and again after the subjects' exposure to some treatment-specific video media. A distinguishing factor of this experiment is that we measured the weight and height of each subject at the end of the experiment and used the actual measures (instead of potentially unreliable measures reported by the subjects themselves) for BMI calculation. We then employed a difference-indifferences regression model to evaluate the relative effectiveness of healthy eating versus anti-obesity advertising content.

To our knowledge, the research summarized here is the first to compare the efficacy of healthy eating and anti-obesity advertising on the WTP for healthy and unhealthy food by BMI. We find that, independent of BMI, both healthy eating advertisements and anti-obesity advertisements are very effective at reducing WTP for unhealthy items; we also find that the magnitude of this baseline effect is much larger for anti-obesity advertisements than for healthy eating advertisements. In addition, we find that the magnitude of the advertising effect rises with BMI.

The remainder of this paper is organized as follows. The next section describes the experiment and data collection. The subsection after that presents the empirical model used to study the impact of advertising on 
subjects' WTP. Finally, in the last two sections, we analyze and explain our empirical findings and discuss their implications as well as offer information that we believe will be critically useful to the design and implementation of advertising campaigns aimed at encouraging people to eat more healthily.

\section{Methodology}

\section{Experimental Design}

A total of 183 adults (non-students) participated in the experiment, which used a within-subjects design. Subjects were paid $\$ 30$ in cash for their participation and were advised that they could use some of this money to purchase snack items presented in a series of auctions. All sessions took place between meal times, either between breakfast and lunch or between lunch and dinner.

We conducted the experiment in two locations to ensure a sufficiently large number of observations of subjects with a wide range of BMIs. There were 75 of the 183 subjects who participated in sessions held in the first location, a small conference room in a local shopping mall, whereas the remaining 108 attended a session in the second location, an experimental economics laboratory belonging to a northeastern university. When conducting experiments at the shopping mall, we had a recruitment table in front of the conference room, along with a sign advertising the experiment. The sign informed potential subjects of the experiment's type, duration, and compensation, and people who expressed interest were then given a detailed written description of what the experiment entailed (see appendix). Participants could then sign up for one of the sessions that would be held on that day. By contrast, subjects participating in the on-campus experiment were recruited by an online announcement that had been sent to all university (non-students) staff via a staff newsletter. Subjects at both locations were randomly assigned into one of three groups: (1) a control group ( $n=60),(2)$ an anti-obesity advertising treatment $(n=60)$, and (3) a healthy eating advertising treatment $(n=63)$.

Each session of the experiment began with our providing the subjects with written and oral instructions on how the auction and bidding process worked. We used the Becker-DeGroot-Marschak (Becker, DeGroot and Marschak 1964) auction (BDM) to elicit subjects' WTP for certain snack food and beverage items. The BDM mechanism is an ideal auction system for our experiment because it is incentive compatible and demand revealing, which means that it provides economic incentives for subjects to bid their true maximum WTP. In a BDM mechanism, subjects simultaneously submit a bid to purchase a good. Afterwards, a "sale" price is randomly drawn from a distribution of prices around the retail value of the item. Any bidder who submits a bid greater than the "sale" price receives the good and pays an amount equal to the sale price. Before the BDM auction was described, 
subjects were informed that one of the auctioned items was randomly selected before the experiment and would become the only binding one (i.e., only one item would actually be sold, even though subjects bid on several items). The purpose of this announcement was to reduce the chance that subjects would submit lower bids due to potential satiation and budget constraint effects. Once all bids were submitted, the pre-selected binding item was revealed and a random market price for the item was drawn. The subjects whose bids were higher than the randomly drawn market price ended up purchasing the binding item for the market price, using a portion of their $\$ 30$ participation endowment.

To ensure that the subjects understood the mechanisms of the bidding process, two practice rounds were held in which subjects submitted bids for a one-dollar bill and a pen. In these practice rounds, the administrator explained why it is always best to bid one's true maximum WTP for the item, because, for example, bidding lower than $\$ 1.00$ for the dollar bill might result in foregoing an opportunity to purchase it at a price lower than $\$ 1.00$. After the practice rounds, the subjects were then asked to submit their maximum WTP for eight snack or beverage items (four healthy and four unhealthy) presented by the administrator. The items included: a Fuji apple weighing about 150 grams, an orange weighing about 150 grams, a 591-milliliter bottle of Aquafina (or Dasani) water, a 591-milliliter bottle of Diet Coke (or Diet Pepsi) $^{3}$, a 591-milliliter bottle of Coca-Cola (or Pepsi), a bag of Lay's Classic potato chips weighing 81.5 grams, a bag of Oreo cookies weighing 57 grams, and a Snickers candy bar weighing 52.7 grams. The retail price of each of these items at the time of the experiments ranged from $\$ 1.00$ to $\$ 1.50$.

After the first round of auctions, subjects were shown a video mix of television show excerpts and, in the case of the two treatment groups, several advertisements that were unique to each treatment. Participants in the control group watched four short clips (totaling 7 minutes in duration) of the television show "Portlandia" and did not see any advertisements. Subjects in the healthy eating advertising treatment viewed the same "Portlandia" clips as were shown to the control group, but they also viewed, in alternation with the "Portlandia" clips, six healthy eating advertisements, for a total viewing experience of 11.3 minutes in duration. Subjects in the anti-obesity advertising treatment viewed the same "Portlandia" clips as were shown to the control group and healthy eating advertisements treatment, but also viewed, in alternation with the "Portlandia" clips, six anti-obesity advertisements, for a total viewing experience of 11.4 minutes in duration. ${ }^{4}$

After the participants were done watching their respective video clips, they were asked to re-submit their bids in a second auction of the same eight food

\footnotetext{
3 We do not include the WTP data for Diet Coke in our data analysis because there is some controversy over whether it should be considered a healthy or an unhealthy item.

4 Details about the advertisement content are provided in the appendix.
} 
and beverage items. Subjects were informed that their bids could be either the same as or different from their previous bids, as they liked.

After finishing the second auction, subjects completed a questionnaire asking them about their attitudes towards the advertisements they had seen (if any), how hungry they were, and their demographic, physical, and socioeconomic characteristics, along with their height and weight. Researchers also took measurements of each subject's height and weight to obtain objective data for these measures, which, as stated, when provided by subjects themselves tend to be inaccurate (Roland 1990; Spencer et al. 2007). We then used the objectively obtained data to calculate the BMI of each individual.

\section{Econometric Model}

Our within-subject experimental design allowed us to observe outcome variables for each individual both before and after that individual's exposure to the video media, with respect to both the control and treatment groups. Therefore, we use a difference-in-differences econometric model to capture the treatment effects. The dependent variable in our estimation is the difference in WTP for an item from the pre-media to post-media auction. Thus, a negative (or positive) value indicates a decrease (or increase) in the WTP for an item after exposure to the media, while a zero value signifies no change.

Because the main purpose of this study is to analyze whether and how the impact of advertising content varies with BMI, we estimate three specifications corresponding to the three levels of BMI classification identified above. In addition to treatment fixed effects, we also include interactions of treatment fixed effects with measures of BMI. More specifically, we estimate two sets of difference-in-differences equations (one for healthy items and one for unhealthy items) for each classification. Thus, the econometric specification that captures the treatment effect along with its interaction with BMI is:

$$
\Delta \mathrm{WTP}_{i l}=\beta_{0}+\sum_{j=1}^{2} \beta_{j}{ }^{*} \operatorname{TREAT}_{j}+\sum_{j=1}^{2} \gamma_{j}^{*} \operatorname{TREAT}_{j}{ }^{*} \mathrm{BMI}_{i}+\delta_{\mathrm{l}}+\varepsilon_{i l},
$$

where $\Delta \mathrm{WTP}_{\mathrm{il}}$ is the difference in the $i^{\text {th }}$ subject's WTP for the $l^{\text {th }}$ item between the pre- and post-media auctions. $\operatorname{TREAT}_{j}=$ \{healthy eating advertisements; anti-obesity advertisements $\}$ is a dummy variable for each of the two advertising treatments. BMI $_{i}$ represents the individual's BMI classification depending on the classification's level of granularity (see the next section for the three categories' definitions). Lastly, $\delta_{1}$ captures the product fixed effects. We estimate this equation separately for healthy and unhealthy items. Because this is a within-subject design, and the left-hand side of the estimated equation is the first difference in WTP for the same individual, the 
observable and unobservable characteristics that are associated with consumer $i$ (e.g., demographics or socioeconomic variables) and which would presumably also influence bidding behavior are differenced out ${ }^{5}$. However, Because we observe multiple bids from each participant for several items, we correct standard errors by calculating clustered robust standard errors-i.e., we allow observations within the same individual to be correlated. We also examine whether there is a nonlinear (inverse U-shaped) relationship between the subject's BMI and WTP by including an interaction term of the treatment effect and BMI-squared, but find no statistical significance.

\section{Results}

\section{Descriptive Statistics}

Figure 1 shows a histogram of BMIs for all of the 183 subjects who participated in the experiment. This histogram plots the number of participants whose BMI fell within each two-point range starting with 18 and ending at 54. We experimented with various ways of incorporating the information about the BMI into our data analysis, ranging from a very coarse division (normalweight vs. overweight) to a very fine categorization (continuous measure of BMI). For robustness, we ultimately classified individuals into three BMI classifications, with an increasing level of granularity: (1) normal-weight vs. overweight; (2) 10 bins representing BMI percentiles in tenths (see right panel of Figure 1); and (3) a continuous measure of BMI. For the most coarse division (1), we used the definitions of the World Health Organization (WHO) to divide our subjects into the two groups: those classified as normal-weight were those with a BMI lower than $25(n=84)$, while those classified as overweight had a BMI greater-than-or-equal to $25(n=99)^{6}$. For the second, finer classification (2), we created a variable representing one of each of the 10 ranges of percentiles, resulting in 10 groups each with an equal number of participants. Subjects with the lowest BMI $\left(1^{\text {st }}-10^{\text {th }}\right.$ percentiles $)$ were assigned a value of 1 (the first bin), and subjects with the largest BMI $\left(91^{\text {st }}\right.$ $100^{\text {th }}$ percentiles) were assigned a value of 10 -and so on. The precise BMI

\footnotetext{
5 Each type of advertising has a different informational content; thus it is possible that the impact of advertising could potentially vary by treatment and the subjects' educational levels. Thus we also estimate a specification where we include an interaction term between education level and treatment effect, but the interaction effect turns out to be statistically insignificant.

6 Ideally, we would prefer to have interaction terms with dummy variables for overweight and obese subjects separately. However, in our sample overweight but not obese, and obese individuals separately were under-represented relative to normal weight individuals. As a result, we subsequently grouped obese and overweight individuals into one 'overweight' category. Because of this, we include two specifications with a more granular and continuous BMI division (classifications (2) and (3)).
} 


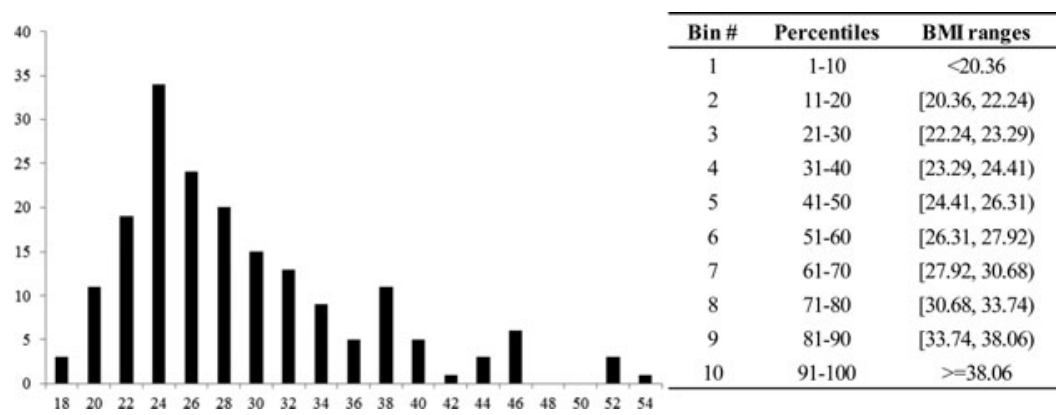

Figure 1. Histogram and Percentiles of Participants' BMI

ranges for each of the 10 bins are reported on the right side of Figure 1. For the finest classification (3), we used the continuous measure of calculated BMI, which in our subjects ranged from 17.2 to 52.8 (mean $=28.13$, standard deviation $=7.40$ ).

First, we discuss our results based on the coarsest division of subjects according to BMI: normal-weight vs. overweight. Table 1 summarizes the outcome variables: average differences in WTP from before and after the subjects were shown the video media, expressed as proportional changes for convenience of interpretation. As expected, there is very little change in WTP in the control treatment; exposure to the "Portlandia" clips with no advertising resulted, on average, in very small-to-insignificant changes in bidding behavior. The dependent variable values, however, are very different for the two advertising treatments. In the anti-obesity advertisements treatment, the WTP for healthy items increased, on average, by 33 percent for overweight individuals and by 16 percent for normal-weight individuals. The changes in WTP for unhealthy items were even more pronounced: for normal-weight individuals it decreased by 29 percent and for overweight individuals by 41 percent. In the healthy eating advertisements treatment, changes were generally in the same direction as in the anti-obesity advertisements treatment, but smaller in magnitude, especially with respect to unhealthy items. Standard deviations for all treatment groups and both types of items were larger for overweight individuals, suggesting a greater degree of heterogeneity in the effect of advertising on purchasing behavior among overweight individuals than on normal-weight individuals.

A similar result can be seen graphically in Figures 2 and 3. Using the bids submitted after exposure to the video media, we plotted the computed demand curves for healthy and unhealthy items for both normal-weight and overweight subjects across the three treatments. These figures depict graphically how the two consumer groups have significantly different responses to the two advertising treatments. Figure 2 shows how both healthy food advertisements and anti-obesity advertisements increase the 
Table 1. Summary Statistics of Proportional Changes in WTP for Healthy and Unhealthy Items by Treatment and Subject's BMI (Normal-Weight $=$ if BMI $<25$; Overweight $=$ if BMI $\geqslant 25$ )

\begin{tabular}{|c|c|c|c|c|c|c|}
\hline & \multirow{2}{*}{\multicolumn{2}{|c|}{ Control }} & \multicolumn{2}{|c|}{ Treatments } & & \\
\hline & & & Anti-Obesit & ertising & \multicolumn{2}{|c|}{ Healthy Eating Advertising } \\
\hline & Normal-Weight & Overweight & Normal-Weight & Overweight & Normal-Weight & Overweight \\
\hline \multirow[t]{2}{*}{ Healthy items } & 0.048 & 0.011 & 0.161 & 0.335 & 0.153 & 0.291 \\
\hline & $(0.245)$ & $(0.110)$ & $(0.452)$ & $(1.029)$ & $(0.400)$ & $(0.632)$ \\
\hline \multirow[t]{2}{*}{ Unhealthy items } & 0.017 & -0.011 & -0.288 & -0.419 & -0.175 & -0.273 \\
\hline & $(0.269)$ & $(0.132)$ & $(0.398)$ & $(0.420)$ & $(0.340)$ & $(0.394)$ \\
\hline
\end{tabular}

Notes: Proportional difference $=[$ WTP(round 2)-WTP(round 1)]/WTP(round 1); standard deviations in parentheses. 

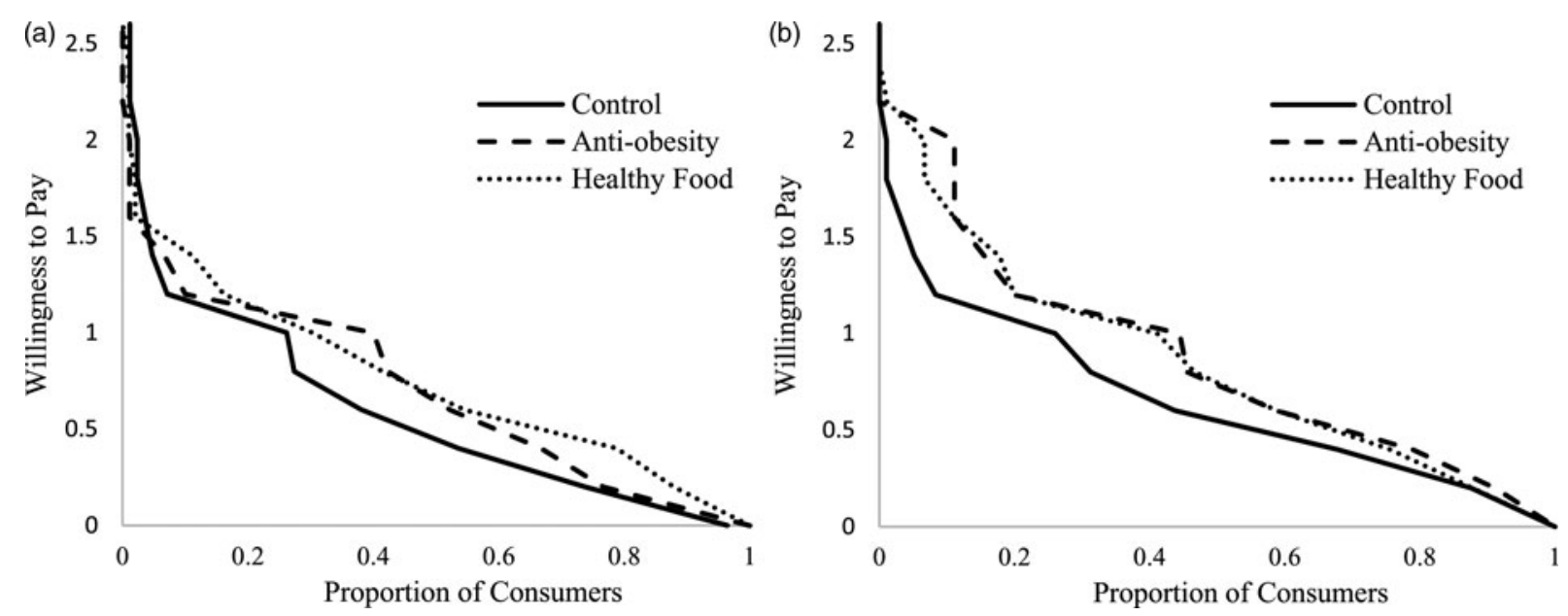

Figure 2. Empirical Demand Schedules for Healthy Items Across Treatments (a) Normal-weight, (b) Overweight 

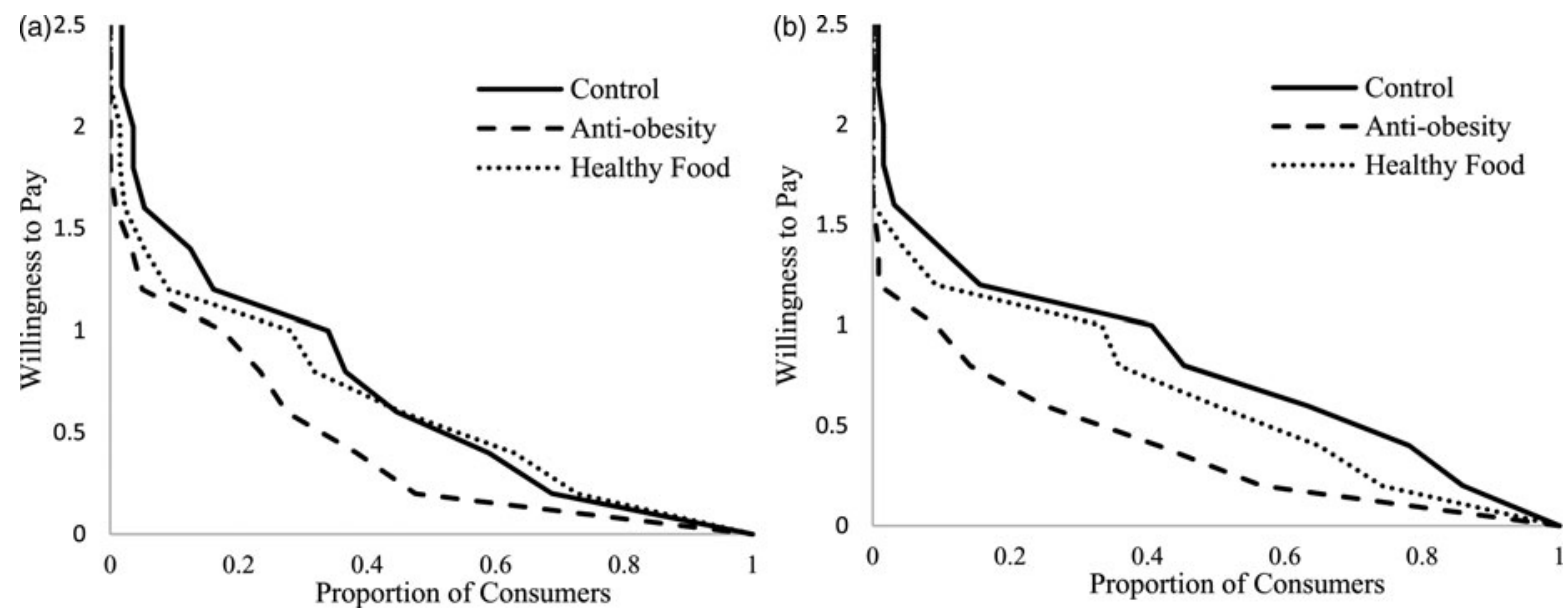

Figure 3. Empirical Demand Schedules for Unhealthy Items Across Treatments (a) Normal-weight (b) Overweight 
demand curve for healthy items, with the largest increase among overweight individuals. Figure 3 shows how anti-obesity advertisements lead to a larger decrease in the demand curve for unhealthy items than healthy eating advertisements do. Again, this decrease is even more pronounced among overweight individuals.

Figure 4 illustrates the average changes in WTP across the three treatments and three levels of BMI classification, from the coarsest classification level (normal-weight vs. overweight) to the finest (by a continuous measure of BMI). Each panel in this figure shows changes in WTP for healthy and unhealthy items, with the changes organized according to ascending BMI. It is clear from this figure that both types of advertising systematically affected the subjects' WTP, whereas any changes in WTP among the control group are small and idiosyncratic. It isalso clear that, in both advertising treatments, the decreases in WTP for unhealthy items are larger in magnitude than increases in WTP for healthy items. Moreover, the effects of both types of advertising clearly increase with BMI levels, independent of the BMI distribution aggregation level.

Table 2 presents demographic and socioeconomic information as well as selfreported current state information (i.e., if the subject felt hungry or thirsty at the time of the experiment) for all subjects in the two coarse groups: normalweight and overweight. Among the 183 subjects who participated in the experiment, 54.1 percent were overweight or obese (according to their BMI), 61.5 percent were Caucasian, 61.5 percent were female, 73.2 percent considered themselves to be their household's primary food shopper, and 38.6 percent had household earnings ranging from $\$ 40,000$ to $\$ 80,000$ per year. The average age of the subjects was 38.3 years old, and the average BMI was 28.2. Our subject pool's BMI distribution is fairly representative of the national U.S. sample, for which the average BMI is reported to be 28.7 (Flegal et al. 2012). Compared with normal-weight subjects, the overweight subjects had a much higher average BMI (33.2 vs. $22.2 ; t(181))=14.850, \mathrm{p}<0.01)$. Among the normal-weight subjects, 83.9 percent believed their bodies to be in good health, while 60.8 percent of the overweight subjects believed the same about themselves. Overall, subjects reported a higher perceived impact of the anti-obesity advertising (7.950) than the healthy eating advertising $(6.587 ; t(121)=9.880, \mathrm{p}<0.01)$. In our data we also observe two welldocumented relationships: lower-income and lower-education individuals are more likely to be overweight. Specifically, we see that lower proportion of overweight individuals have college degrees (32.2 percent overweight vs. 39.3 percent normal weight) or, to even greater extent, graduate degrees (19.3 percent overweight vs. 30.73 percent normal-weight). We also see that overweight individuals tend to earn, on average, less than normal-weight individuals (40.4 percent of overweight individuals vs. 32.8 percent of normal-weight individuals earn less than $\$ 40,000$ ).

As stated, we asked our subjects to report their own height and weight in the questionnaire they were given. We also later measured the height and weight of 

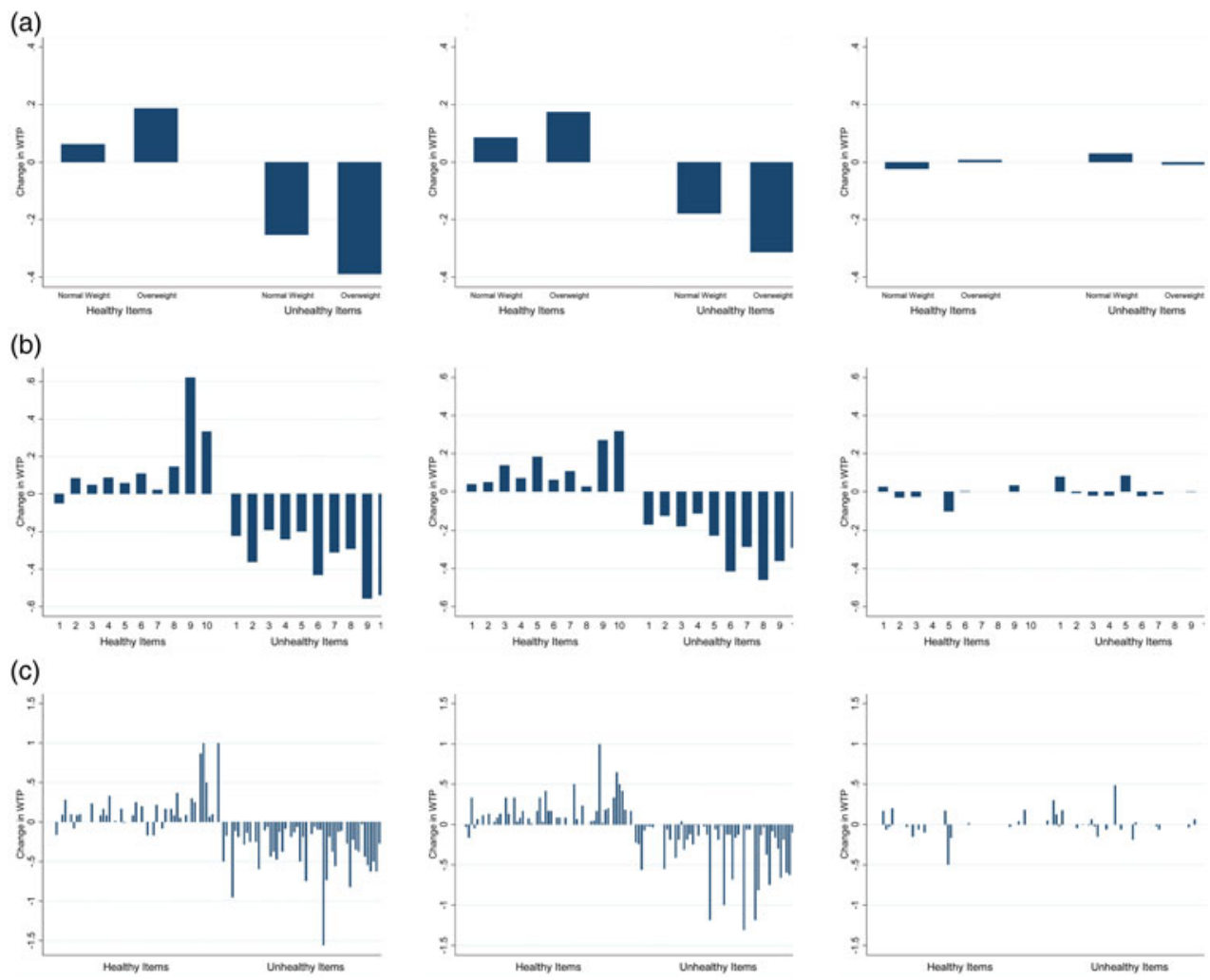

Figure 4. Changes in Average WTP by Treatment and BMI (a) By Normal-weight vs. Overweight (b) By BMI Percentile Bins $\left(1=\right.$ lowest $10^{\text {th }}$ percentile; $10=$ highest $10^{\text {th }}$ percentile; Bins 6 through 10 represent individuals with $\left.B M I \geqslant 25\right)$ (c) By observed BMI (left to right-lowest to highest BMI level; individual observations) 
Table 2. Descriptive Statistics (means and Standard Deviation) of WTP and Subjects' Sociodemographic Information by Treatment and Subject's BMI (Normal-Weight $=$ if BMI $<25$; Overweight $=$ if BMI $\geqslant 25$ )

\begin{tabular}{|c|c|c|c|c|c|c|}
\hline \multirow[b]{2}{*}{ Variables } & \multicolumn{2}{|c|}{ Control group } & \multicolumn{2}{|c|}{ Anti-obesity advertising } & \multicolumn{2}{|c|}{ Healthy eating advertising } \\
\hline & Overweight & Normal-Weight & Overweight & Normal-Weight & Overweight & Normal-Weight \\
\hline BMI & $\begin{array}{l}33.548 \\
(5.701)\end{array}$ & $\begin{array}{l}21.936 \\
(2.042)\end{array}$ & $\begin{array}{l}32.540 \\
(6.604)\end{array}$ & $\begin{array}{l}22.461 \\
(1.687)\end{array}$ & $\begin{array}{l}33.436 \\
(7.117)\end{array}$ & $\begin{array}{l}22.125 \\
(2.113)\end{array}$ \\
\hline Age & $\begin{array}{c}39.727 \\
(13.960)\end{array}$ & $\begin{array}{c}38.815 \\
(15.393)\end{array}$ & $\begin{array}{c}42.218 \\
(14.640)\end{array}$ & $\begin{array}{c}37.385 \\
(13.211)\end{array}$ & $\begin{array}{c}39.294 \\
(13.757)\end{array}$ & $\begin{array}{c}34.827 \\
(15.091)\end{array}$ \\
\hline Male & $\begin{array}{c}0.393 \\
(0.490)\end{array}$ & $\begin{array}{c}0.370 \\
(0.556)\end{array}$ & $\begin{array}{c}0.438 \\
(0.557)\end{array}$ & $\begin{array}{c}0.384 \\
(0.488)\end{array}$ & $\begin{array}{c}0.471 \\
(0.500)\end{array}$ & $\begin{array}{c}0.345 \\
(0.476)\end{array}$ \\
\hline Married & $\begin{array}{c}0.606 \\
(0.778)\end{array}$ & $\begin{array}{c}0.370 \\
(0.484)\end{array}$ & $\begin{array}{c}0.531 \\
(0.500)\end{array}$ & $\begin{array}{c}0.500 \\
(0.501)\end{array}$ & $\begin{array}{c}0.647 \\
(0.537)\end{array}$ & $\begin{array}{c}0.483 \\
(0.501)\end{array}$ \\
\hline Children & $\begin{array}{c}0.424 \\
(0.495)\end{array}$ & $\begin{array}{c}0.185 \\
(0.389)\end{array}$ & $\begin{array}{c}0.156 \\
(0.364)\end{array}$ & $\begin{array}{c}0.423 \\
(0.568)\end{array}$ & $\begin{array}{c}0.324 \\
(0.469)\end{array}$ & $\begin{array}{c}0.207 \\
(0.406)\end{array}$ \\
\hline Caucasian & $\begin{array}{c}0.636 \\
(0.482)\end{array}$ & $\begin{array}{c}0.518 \\
(0.501)\end{array}$ & $\begin{array}{c}0.563 \\
(0.497)\end{array}$ & $\begin{array}{c}0.692 \\
(0.463)\end{array}$ & $\begin{array}{c}0.647 \\
(0.479)\end{array}$ & $\begin{array}{c}0.586 \\
(0.494)\end{array}$ \\
\hline Asian & $\begin{array}{c}0.121 \\
(0.327)\end{array}$ & $\begin{array}{c}0.148 \\
(0.356)\end{array}$ & $\begin{array}{c}0.219 \\
(0.414)\end{array}$ & $\begin{array}{c}0.231 \\
(0.422)\end{array}$ & $\begin{array}{c}0.059 \\
(0.236)\end{array}$ & $\begin{array}{c}0.241 \\
(0.429)\end{array}$ \\
\hline Some college without degree & $\begin{array}{c}0.212 \\
(0.410)\end{array}$ & $\begin{array}{c}0.269 \\
(0.447)\end{array}$ & $\begin{array}{c}0.250 \\
(0.434)\end{array}$ & $\begin{array}{c}0.154 \\
(0.362)\end{array}$ & $\begin{array}{c}0.235 \\
(0.425)\end{array}$ & $\begin{array}{c}0.172 \\
(0.379)\end{array}$ \\
\hline College degree & $\begin{array}{c}0.303 \\
(0.460)\end{array}$ & $\begin{array}{c}0.346 \\
(0.477)\end{array}$ & $\begin{array}{c}0.281 \\
(0.450)\end{array}$ & $\begin{array}{c}0.385 \\
(0.488)\end{array}$ & $\begin{array}{c}0.382 \\
(0.487)\end{array}$ & $\begin{array}{c}0.448 \\
(0.498)\end{array}$ \\
\hline Graduate degree & $\begin{array}{c}0.152 \\
(0.359)\end{array}$ & $\begin{array}{c}0.269 \\
(0.445)\end{array}$ & $\begin{array}{c}0.281 \\
(0.450)\end{array}$ & $\begin{array}{c}0.346 \\
(0.477)\end{array}$ & $\begin{array}{c}0.147 \\
(0.355)\end{array}$ & $\begin{array}{c}0.207 \\
(0.406)\end{array}$ \\
\hline Income less than $\$ 40,000$ & $\begin{array}{c}0.455 \\
(0.499)\end{array}$ & $\begin{array}{c}0.308 \\
(0.463)\end{array}$ & $\begin{array}{c}0.406 \\
(0.492)\end{array}$ & $\begin{array}{c}0.333 \\
(0.473)\end{array}$ & $\begin{array}{c}0.353 \\
(0.479)\end{array}$ & $\begin{array}{c}0.345 \\
(0.476)\end{array}$ \\
\hline
\end{tabular}


Table 2. Continued

\begin{tabular}{|c|c|c|c|c|c|c|}
\hline \multirow[b]{2}{*}{ Variables } & \multicolumn{2}{|c|}{ Control group } & \multicolumn{2}{|c|}{ Anti-obesity advertising } & \multicolumn{2}{|c|}{ Healthy eating advertising } \\
\hline & Overweight & Normal-Weight & Overweight & Normal-Weight & Overweight & Normal-Weight \\
\hline Income from $\$ 40,000$ to $\$ 80,000$ & $\begin{array}{c}0.394 \\
(0.490)\end{array}$ & $\begin{array}{c}0.500 \\
(0.501)\end{array}$ & $\begin{array}{c}0.468 \\
(0.500)\end{array}$ & $\begin{array}{c}0.333 \\
(0.473)\end{array}$ & $\begin{array}{c}0.265 \\
(0.442)\end{array}$ & $\begin{array}{c}0.379 \\
(0.486)\end{array}$ \\
\hline Primary shopper & $\begin{array}{c}0.727 \\
(0.446)\end{array}$ & $\begin{array}{c}0.703 \\
(0.458)\end{array}$ & $\begin{array}{c}0.719 \\
(0.450)\end{array}$ & $\begin{array}{c}0.807 \\
(0.395)\end{array}$ & $\begin{array}{c}0.676 \\
(0.468)\end{array}$ & $\begin{array}{c}0.724 \\
(0.447)\end{array}$ \\
\hline Feeling healthy & $\begin{array}{c}0.697 \\
(0.675)\end{array}$ & $\begin{array}{c}0.889 \\
(0.417)\end{array}$ & $\begin{array}{c}0.438 \\
(0.790)\end{array}$ & $\begin{array}{c}0.730 \\
(0.593)\end{array}$ & $\begin{array}{c}0.697 \\
(0.628)\end{array}$ & $\begin{array}{c}0.896 \\
(0.403)\end{array}$ \\
\hline Hungry & $\begin{array}{c}0.423 \\
(0.495)\end{array}$ & $\begin{array}{c}0.381 \\
(0.487)\end{array}$ & $\begin{array}{c}0.360 \\
(0.481)\end{array}$ & $\begin{array}{c}0.440 \\
(0.498)\end{array}$ & $\begin{array}{c}0.571 \\
(0.496)\end{array}$ & $\begin{array}{c}0.320 \\
(0.468)\end{array}$ \\
\hline Thirsty & $\begin{array}{c}0.634 \\
(0.477)\end{array}$ & $\begin{array}{c}0.428 \\
(0.496)\end{array}$ & $\begin{array}{c}0.800 \\
(0.401)\end{array}$ & $\begin{array}{c}0.600 \\
(0.491)\end{array}$ & $\begin{array}{c}0.821 \\
(0.384)\end{array}$ & $\begin{array}{c}0.640 \\
(0.481)\end{array}$ \\
\hline Never snack & $\begin{array}{c}0.364 \\
(0.481)\end{array}$ & $\begin{array}{c}0.308 \\
(0.463)\end{array}$ & $\begin{array}{c}0.344 \\
(0.476)\end{array}$ & $\begin{array}{c}0.231 \\
(0.422)\end{array}$ & $\begin{array}{c}0.235 \\
(0.425)\end{array}$ & $\begin{array}{c}0.379 \\
(0.486)\end{array}$ \\
\hline Snack occasionally & $\begin{array}{c}0.606 \\
(0.490)\end{array}$ & $\begin{array}{c}0.577 \\
(0.495)\end{array}$ & $\begin{array}{c}0.531 \\
(0.500)\end{array}$ & $\begin{array}{c}0.653 \\
(0.477)\end{array}$ & $\begin{array}{c}0.588 \\
(0.493)\end{array}$ & $\begin{array}{c}0.552 \\
(0.498)\end{array}$ \\
\hline Perceived ad impact (from 1 to 10 ) & N.A. & N.A. & $\begin{array}{c}8.250 \\
(2.096)\end{array}$ & $\begin{array}{c}7.500 \\
(2.443)\end{array}$ & $\begin{array}{c}6.559 \\
(2.149)\end{array}$ & $\begin{array}{c}6.621 \\
(1.959)\end{array}$ \\
\hline Number of subjects & 33 & 27 & 32 & 33 & 34 & 29 \\
\hline
\end{tabular}




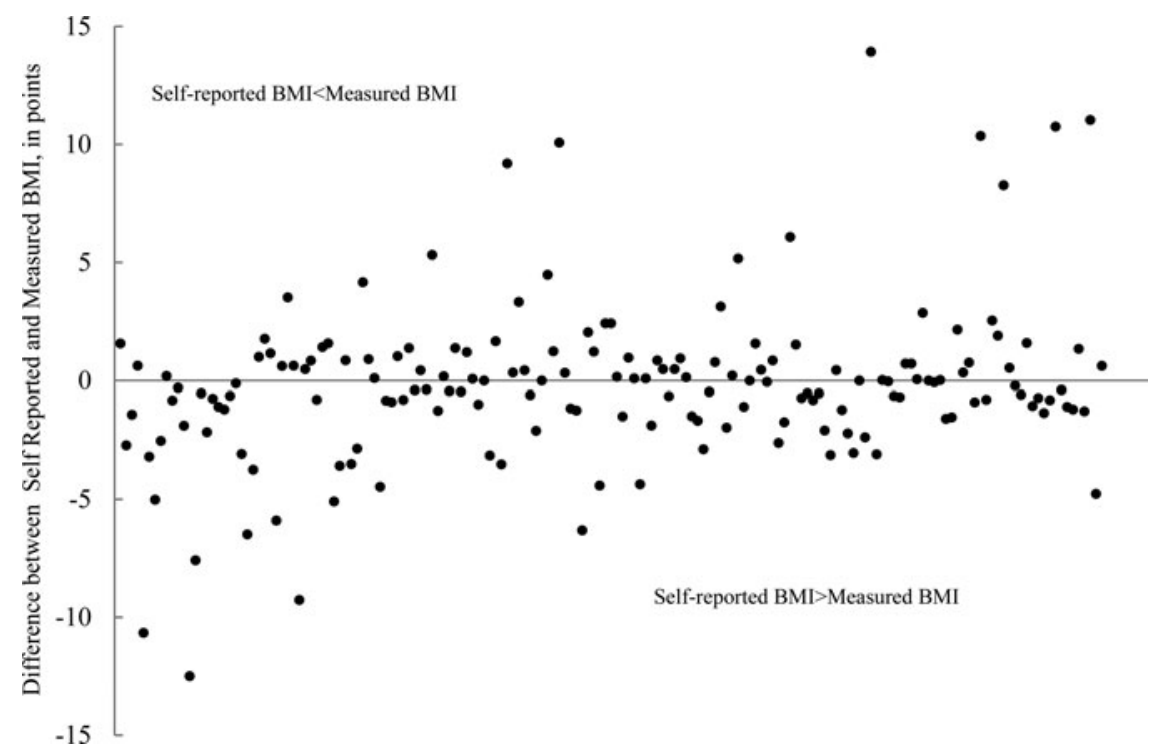

Figure 5. Differences between the Measured and Self-Reported BMI Numbers

each participant, enabling us to compute two sets of BMIs: those reported by the subjects themselves and those measured by us. Figure 5 plots the differences between those two measures. Each dot on this figure represents the discrepancy between the measured BMI and the BMI reported by the same individual. Dots falling in the top half of the graph represent individuals who reported lower BMIs than their actual BMIs, whereas dots falling below the zero axis represent individuals who reported larger BMIs than their actual BMIs. As is evident from this figure, a significant number of our subjects provided highly inaccurate information about their height and/or weight. Interestingly, subjects with lower BMIs were more likely to overreport their BMIs while subjects with higher BMIs were more likely to underreport their BMIs. The unreliability of height and weight measures as reported by subjects is a pervasive issue in the related literature (Roland 1990; Spencer et al. 2007), but we were able to avoid its complications by using the objectively measured BMI numbers in our analysis instead.

\section{Estimation Results}

Table 3 reports the estimation results. Specification (1) uses a dummy for overweight individuals represented by the $\mathrm{BMI}_{i}$ variable, thus $\gamma_{j}$ can be interpreted as an additional treatment $j$ effect that exists only for the overweight individuals. In this section, we refer to the absolute changes that correspond to the model estimates in Table 3, whereas the next section 
Table 3. Effect of Advertising on WTP: Difference-in-Differences Estimation Results

\begin{tabular}{|c|c|c|c|c|c|c|}
\hline & \multicolumn{2}{|c|}{$\begin{array}{c}\text { (1) BMI: Normal Weight vs. } \\
\text { Overweight }\end{array}$} & \multicolumn{2}{|c|}{ (2) BMI: by 10 Percentile Bins } & \multicolumn{2}{|c|}{ (3) BMI: by Continuous BMI } \\
\hline & $\begin{array}{l}\text { Healthy } \\
\text { Items }\end{array}$ & $\begin{array}{l}\text { Unhealthy } \\
\text { Items }\end{array}$ & $\begin{array}{l}\text { Healthy } \\
\text { Items }\end{array}$ & $\begin{array}{l}\text { Unhealthy } \\
\text { Items }\end{array}$ & Healthy Items & $\begin{array}{l}\text { Unhealthy } \\
\text { Items }\end{array}$ \\
\hline \multirow[t]{2}{*}{ Anti-obesity advertising } & $0.069 * * *$ & $-0.262^{* * *}$ & -0.067 & $-0.199 *$ & $-0.300^{*}$ & -0.016 \\
\hline & $(0.025)$ & $(0.064)$ & $(0.058)$ & $(0.110)$ & $(0.171)$ & $(0.172)$ \\
\hline \multirow{2}{*}{$\begin{array}{l}\text { Healthy eating } \\
\text { advertising }\end{array}$} & $0.092^{* * *}$ & $-0.187^{* * *}$ & 0.006 & $-0.106^{*}$ & $-0.216^{* *}$ & 0.019 \\
\hline & $(0.026)$ & $(0.048)$ & $(0.046)$ & $(0.058)$ & $(0.104)$ & $(0.138)$ \\
\hline \multirow[t]{2}{*}{ Anti-obesity adv. * BMI } & $0.105^{*}$ & -0.136 & $0.035^{* *}$ & -0.025 & $0.015^{* *}$ & $-0.011^{* *}$ \\
\hline & $(0.056)$ & $(0.086)$ & $(0.014)$ & $(0.016)$ & $(0.007)$ & $(0.005)$ \\
\hline \multirow[t]{2}{*}{ Healthy eating adv. * BMI } & 0.048 & $-0.135^{*}$ & $0.021^{* *}$ & $-0.028^{* *}$ & $0.012^{* * *}$ & $-0.010^{* *}$ \\
\hline & $(0.063)$ & $(0.077)$ & $(0.009)$ & $(0.011)$ & $(0.004)$ & $(0.005)$ \\
\hline \multirow[t]{2}{*}{ Constant } & 0.019 & $-0.070^{* *}$ & 0.019 & $-0.070^{* *}$ & 0.019 & $-0.071^{* *}$ \\
\hline & $(0.017)$ & $(0.032)$ & $(0.017)$ & $(0.032)$ & $(0.017)$ & $(0.032)$ \\
\hline $\mathrm{R} 2$ & 0.057 & 0.154 & 0.091 & 0.157 & 0.103 & 0.150 \\
\hline Num. of observations & 548 & 731 & 548 & 731 & 542 & 723 \\
\hline
\end{tabular}

Note: ${ }^{* * *} \mathrm{p}<0.01,{ }^{* *} \mathrm{p}<0.05,{ }^{*} \mathrm{p}<0.1$; Robust clustered standard errors; item fixed effects included in all of the specifications. Specification (1): BMI is an indicator variable for overweight individuals (BMI > 25); Specification (2): BMI takes value of 1 to 10 by percentile bins (see Figure 1); Specification (3): BMI is a continuous variable corresponding to an actual measured BMI with outlier observations (BMI in the 99th percentile and above) excluded. 


\section{Table 4. Effect of Advertising on WTP: Summary of Estimation Results (in percent changes)}

\begin{tabular}{lcccc}
\hline & \multicolumn{4}{c}{ Treatments } \\
\cline { 2 - 5 } & $\begin{array}{l}\text { Anti-Obesity } \\
\text { Normal-Weight } \\
\text { (\%) }\end{array}$ & $\begin{array}{l}\text { Advertising } \\
\text { Overweight } \\
\text { (\%) }\end{array}$ & $\begin{array}{l}\text { Healthy Eating } \\
\text { Normal-Weight } \\
\text { (\%) }\end{array}$ & $\begin{array}{l}\text { Advertising } \\
\text { Overweight } \\
\text { (\%) }\end{array}$ \\
\hline $\begin{array}{l}\text { Healthy items } \\
\text { Unhealthy } \\
\text { items }\end{array}$ & 12.19 & 26.40 & 14.60 & 13.75 \\
\hline
\end{tabular}

summarizes and discusses in proportional terms the results presented in Table 4.

At the baseline level, independent of BMI, both types of advertising were observed to be effective at increasing subjects' WTP for healthy items. The effect was larger, however, as a result of the healthy eating advertisements (0.092 vs. 0.069). Both types of advertisements were also observed as effective at decreasing subjects' WTP for unhealthy items. The magnitude of this effect (i.e., a decrease in WTP for unhealthy food) is (i) two to three times larger than the effect of increased demand for healthy items $(-0.262 \mathrm{vs}$. 0.069 and -0.187 vs. 0.092 ), and (ii) much larger as a result of the anti-obesity advertisements than of the healthy eating advertisements ( -0.262 vs. -0.187$)$. Furthermore, there were additional significant effects of both kinds of advertising on those of our subjects who were overweight. Specifically, the antiobesity advertisements had an additional positive (0.105) effect on WTP for healthy items, but only for the overweight individuals. Overweight individuals also demonstrated a greater decrease in WTP for unhealthy items, but only significantly as a result of the healthy eating advertising.

Specification (2) uses $10 \mathrm{BMI}$ percentile bins for the $\mathrm{BMI}_{i}$ variable. As a result, $\gamma_{j}$ can be interpreted as an additional treatment $j$ effect as one moves in sets of $10^{\text {th }}$ percentiles in the BMI distribution (e.g., from the $10^{\text {th }}$ to $20^{\text {th }}$ percentile or from the $40^{\text {th }}$ to $50^{\text {th }}$ percentile). In this specification, we find no baseline treatment effect for healthy items; however, we find strong and significant effects that vary by the BMI percentile bins. Because the excluded bin is Bin $\# 1$, this means that individuals with the lowest BMI $\left(1^{\text {st }}-10^{\text {th }}\right.$ percentiles $)$ are not affected by advertisements. However, everyone else (90 percent of our sample) is affected, and this effect is linearly increasing or decreasing by the BMI bins. ${ }^{7}$ The effect of anti-obesity advertisements on WTP for healthy

\footnotetext{
7 The result that in the first specification the baseline effects were significant and in the specification (2) they are not is easily reconcilable: the baseline effects in the second and third specifications are attributable only to the individuals falling in the $1^{\text {st }}-10^{\text {th }}$ BMI percentiles. A
} 
items is marginally greater than the effect of healthy eating advertisements (0.035 vs. 0.021$)$. Moreover, this effect is increasing with BMI: the individuals with the highest BMI had the largest reactions. For example, as one moves from the second bin $\left(11^{\text {th }}-20^{\text {th }}\right.$ percentiles by BMI $)$ to the third bin $\left(21^{\text {st }}\right.$ $30^{\text {th }}$ percentiles by BMI), the WTP for healthy items increases by an additional 0.035. If one moves from the second bin to the tenth bin $\left(91^{\text {st }}\right.$ $100^{\text {th }}$ percentiles by BMI), then WTP decreases by an additional $0.035^{*} 9=$ 0.315 . As for the effects of the healthy eating advertisements: these patterns are similar, but the numbers are much smaller in magnitude (i.e., an increase in WTP by $0.021 * 9=0.189$ ). As to the unhealthy items, even individuals in the lowest percentiles (i.e., $1^{\text {st }}-10^{\text {th }}$, or baseline Bin \#1) reduce their WTP, and the effects of anti-obesity advertisements in this respect is approximately double the magnitude of those of the healthy eating advertisements. However, the interaction of healthy eating advertisements and BMI percentiles is significant and negative $(-0.028)$, implying that as we move up in the distribution of BMI, WTP for unhealthy items decreases more and more with each BMI bin.

Specification (3) uses a continuous measure of $\mathrm{BMI}^{8}$, for the $\mathrm{BMI}_{i}$ variable. The results are largely consistent with those of specifications (1) and (2): the advertising effect is larger as a result of the anti-obesity advertisements and increases in magnitude with BMI. More specifically, we find that in addition to the baseline level of treatment fixed effects, each point in BMI decreases WTP for unhealthy items by an additional 0.011 in response to anti-obesity advertisements and by an additional 0.010 in response to healthy eating advertisements. WTP for healthy items increases by an additional 0.015 in response to anti-obesity advertisements and by an additional 0.012 in response to healthy eating advertisements.

Table 4 summarizes the significant estimation results of specification (1) expressed in terms of percentage changes in WTP relative to the average WTP observed in the pre-treatment auctions, organized by healthy vs. unhealthy items and by weight group.

\section{Discussion}

A major finding of this study is that both healthy eating advertisements and anti-obesity advertisements have a significant impact on all treatment subjects. However, the magnitude of their effect varies according to the subject's BMI. While this is not a surprising result, it is useful to document empirically the degree of effectiveness based on ad content and its target

similar note should be made about the baseline results in specification (3) where the main results are driven by the treatment interaction term with the continuous measure of BMI.

8 Specification (3) excludes two subjects: outliers with a BMI greater than those in the $99^{\text {th }}$ percentile. 
audience. Because we are mainly concerned about the efficacy of the two types of advertising typically employed to encourage overweight people to eat more healthily, we concentrate here on the results for the overweight subjects from the coarser model (Specification (1) in Table 3) and report three significant additional conclusions.

First, it is evident from our results that both healthy eating advertisements and anti-obesity advertisements are effective in increasing the demand for healthy food and beverage items among overweight subjects. The anti-obesity advertisements shown in our experiment increased overweight subjects' WTP for healthy items by 26.40 percent, while the healthy eating advertisements increased overweight subjects' WTP for healthy items by 13.75 percent. In other words, the anti-obesity advertisements were about twice as effective as the healthy eating advertisements in increasing WTP for healthy items among these subjects.

Second, both healthy eating advertisements and anti-obesity advertisements were seen to be effective in reducing the demand for unhealthy items among overweight subjects. The anti-obesity advertisements shown in our experiment decreased overweight subjects' WTP for unhealthy items by 36.64 percent, while the healthy eating advertisements decreased overweight subjects' WTP for unhealthy items by 35.38 percent. Our results suggest that both types of advertising are significantly more effective in reducing WTP for unhealthy items than in increasing WTP for healthy items. Indeed, the magnitudes here are about twice as large as the corresponding impacts on WTP for healthy items. Thus, there appears to be an asymmetry in the effectiveness of these forms of advertising in decreasing consumers' demand for unhealthy items, relative to increasing their demand for healthy items.

Third, it appears that anti-obesity advertisements are significantly more effective in nudging overweight people towards making healthier food and beverage selections than healthy eating advertisements are $(26.40$ percent vs. 13.75 percent). The anti-obesity advertisements shown in our experiment increased subjects' WTP for healthy items and decreased their WTP for unhealthy items more than the healthy eating advertisements did.

Even though we do not directly measure the stigma effect of anti-obesity advertising, our results suggest that negatively framed anti-obesity advertising, which can be perceived as stigmatizing overweight individuals, has a larger impact (compared with positively framed healthy eating advertising) on the WTP of overweight individuals. This observed asymmetry might be a result of the "negativity effect," a recognized behavioral bias often exploited by the managers of political campaigns, in which negatively framed information consistently tends to have a greater effect on decision-making than a similar, positively framed promotional message (Kahneman and Tversky 1979; Peeters and Czapinski 1990; Levin, Schneider, and Gaeth 1998).

Another possible explanation for the greater effectiveness of the anti-obesity advertisements on overweight individuals is associated with well-documented findings in the literature that overweight individuals tend to be more present 
biased and relatively lacking in self-control, especially in relation to dietary choices (Komlos, Smith, and Bogin 2004; Borghan and Golsteyn 2006; Zhang and Rashad 2008; Ikeda, Kang, and Ohtake 2010; Fan and Jin 2014). Advertising can affect individuals subconsciously through "visceral cues" (Laibson 2001), such as the sight and sound of food. It can also affect decisions by providing information on what constitutes a healthy or unhealthy diet. Possibly, the information about what constitutes a healthy or unhealthy diet present in the healthy eating advertisements may not be sufficient to motivate overweight individuals to alter their behavior. A stronger message, such as the ones in anti-obesity advertising, which tend to contain more visceral cues, might better motivate overweight individuals to change their current dietary habits.

\section{Implications and Concluding Remarks}

In this study we investigate how the impact of healthy eating advertising and anti-obesity advertising on WTP varies by consumer BMI. Using experimental data and the difference-in-differences model, we quantify how advertising affects demand for both healthy and unhealthy food and beverages and we document how these effects vary depending on an individual's BMI. There are several key findings of this research.

First, both types of advertising significantly impact the WTP for normalweight and overweight individuals. As expected, both types of advertising significantly increased the WTP for healthy foods, and decreased the WTP for unhealthy food. Second, both types of advertisements had a larger impact on reducing the WTP for unhealthy food items than increasing the WTP for healthy items. A third finding is that while both types of advertising impacted all subjects in similar directions, the magnitude of impacts in some cases varied significantly. For instance, anti-obesity advertising had over twice the impact on increasing WTP for overweight individuals ( +26.4 percent) compared with normal-weight $(+12.2$ percent $)$. Likewise, healthy food advertising had a 41 percent greater impact on reducing the WTP for unhealthy food for overweight people $(-35.4$ percent $)$ compared with normal-weight individuals $(-25.1$ percent).

The results of our study suggest that different advertising tactics might, in some cases, be more effective on individuals of different weight classes and that advertising content should be carefully designed based on each targeted group. For instance, when targeting overweight people, our results indicate that anti-obesity advertising has twice the positive impact as healthy food advertising on increasing WTP for healthy foods, and about the same impact on reducing WTP for unhealthy foods. While healthy food advertising also impacts WTP for healthy $(+)$ and unhealthy $(-)$ foods for overweight people, the impacts are lower than anti-obesity advertising. Additionally, advertising campaigns aimed at reducing unhealthy food consumption might be more effective than those aimed at increasing healthy food consumption. 
This study adds a new perspective to the current debate over anti-obesity policy. To the best of our knowledge, our study is not only the first to distinguish between the impacts of advertising on normal-weight and overweight individuals; it is also the first to compare the impacts of two different types of advertising across these two groups. As a result, we have demonstrated empirically that to maximize the efficacy of anti-obesity policies some specialization is in order, in particular the targeting of certain kinds of advertising at at-risk individuals. Also, contrary to previous psychological research (e.g., Brown, 2001; Ruiter, Abraham, and Kock, 2001; Brown and Locker, 2009), our study finds that anti-obesity advertising has significant impacts on WTP for both unhealthy and healthy foods. However, we did not look at the potential stigma effects of this type of advertising.

One caveat of this study, as with any research based on experimental data, is that the generalized application of its results to the field should be undertaken with caution (Levitt and List 2007). We suggest that our results serve as the upper-bound on the potential impacts of advertising. In a nonexperimental setting, people would likely pay less attention to advertising and might make different dietary choices when they know they are not being observed. Though we propose explanations for the varying effects of advertising on the normal-weight and overweight individuals in our experiment, a comprehensive understanding of the precise mechanisms of these effects requires additional study. While we observe the relationship between BMI and the effect of advertising, we cannot make any causal claims about what exactly drives these differences. To this end, we recommend that further research explore these potential mechanisms, in particular additional differences between normal-weight and overweight individuals that may induce or account for different behavior. In addition to continuing to focus on advertising, future studies might also examine the heterogeneous reactions of normal-weight and overweight individuals to other anti-obesity policies, such as fat taxes, thin subsidies, and calorie-content and nutrition labeling.

\section{References}

Amatyakul, W. 2013. The impact of menu labels on changing eating behavior: An experimental study. Unpublished Paper, Cornell University.

Andreyeva, T., F.J. Chaloupka, and K.D. Brownell. 2011. "Estimating the Potential of Taxes on Sugar-Sweetened Beverages to Reduce Consumption and Generate Revenue." Preventive Medicine 52(6): 413-416.

Andreyeva, T., R. Sturm, and J.S. Ringel. 2004. "Moderate and Severe Obesity Have Large Differences in Health Care Costs." Obesity Research 12(12): 1936-1943.

Bassett, M.T., T. Dumanovsky, C. Huang, et al. 2008. "Purchasing Behavior and Calorie Information at Fast-Food Chains in New York City." American Journal of Public Health 98(8): 1457-1459.

Bhattacharya, J., and N. Sood. 2011. "Who Pays for Obesity?" The Journal of Economic Perspectives 25(1): 139-157.

Becker, G.M., M.H. DeGroot, and J. Marschak. 1964. "Measuring Utility by a Single-Response Sequential Method." Behavioral Science 9(3): 226-232. 
Borghan, L., and B.H. Golsteyn. 2006. "Time Discounting and the Body Mass Index: Evidence from the Netherlands." Economics \& Human Biology 4(1): 39-61.

Brown, S., and E. Locker. 2009. "Defensive Responses to an Emotive Anti-Alcohol Message." Psychology and Healthy 24(5): 517-528.

Brown, S. L. (2001) Emotive Health Advertising and Message Resistance. Australian Psychologist 36(3): 193-199.

Burton, S., E.H. Creyer, J. Kees, and K. Huggins. 2006. "Attacking the Obesity Epidemic: The Potential Health Benefits of Providing Nutrition Information in Restaurants." American Journal of Public Health 96(9): 1669-1675.

Cawley, J., and C. Meyerhoefer. 2012. "The Medical Care Costs of Obesity: An Instrumental Variables Approach." Journal of Health Economics 31(1): 219-230.

Chapman, K., P. Nicholas, and R. Supramaniam. 2006. "How Much Food Advertising Is There on Australian Television?" Health Promotion International 21(3): 172-180.

Chouinard, H.H., D.E. Davis, J.T. LaFrance, and J.M. Perloff. 2007. "Fat Taxes: Big Money for Small Change." Forum for Health Economics \& Policy 10(2): 1-30.

Chu, Y.H., E.A. Frongillo, S.J. Jones, and F.L. Kaye. 2009. “Improving Patrons' Meal Selections through the Use of Point-of-Selection Nutrition Labels." American Journal of Public Health 99(11): 2001-2005.

Downs, J.S., G. Lowenstein, and J. Wisdom. 2009. "Strategies for Promoting Healthier Food Choices." American Economics Review 99(2): 159-164.

Dumanovsky, T., C.Y. Huang, C.A. Nonas, et al. 2011. “Changes in Energy Content of Lunchtime Purchases from Fast Food Restaurants after Introduction of Calorie Labelling: Cross Sectional Customer Surveys." British Medical Journal 343: d4464.

Ebel, B., R. Kerch, V.L. Brescoll, and L.B. Dixon. 2009. “Calorie Labeling and Food Choices: A First Look at the Effects on Low-Income People in New York City." Health Affairs 28(6): 1110-21.

Edwards, R.D. 2011. "Commentary: Soda Taxes, Obesity, and the Shifty Behavior of Consumers." Preventive Medicine 52(6): 417-418.

Ellison, B., J.L. Lusk, and D. Davis 2014a. The Value and Cost of Restaurant Calories Labels. Economic Inquiry, 52: 666-681.

— 2014b. "Do Calorie Labels Reduce Caloric Intake? Evidence From Two Full Service Restaurants." Journal of Agricultural and Applied Economics 46(2): 173-191.

Epstein, L.H., K.K. Dearing, L.G. Roba, and E.A. Finkelstein. 2010. "The Influence of Taxes and Subsidies on Energy Purchased in an Experimental Purchasing Study." Psychological Science 21(3): 406-414.

Fan, M., and J. Jin. 2014. "Obesity and Self-Control: Food Consumption, Physical Activity, and Weight-Loss Intention." Applied Economics Perspective and Policy 36(1): 125-145.

Finkelstein, E.A., K.L. Strombotne, N.L. Chan, and J. Krieger. 2011. "Mandatory Menu Labeling in One Fast-Food Chain in King County." American Journal of Preventive Medicine 40(2): 122-127.

Flegal, M.K., M.D. Carroll, B.K. Kit, and C.L. Ogden. 2012. "Prevalence of Obesity and Trends in the Distribution of Body Mass Index among U.S. Adults, 1999-2010." The Journal of American Medical Association 307(5): 483-490.

Fudenberg, D., and D.K. Levine. 2006. "A Dual Self-Model of Impulse Control." American Economic Review 96(5): 1449-1476.

Galizzi, M.M. 2014. "What is Really Behavioral Health Policy? And Does it Work?" Applied Economic Perspectives and Policy 36(1): 25-60.

Harnack, L.J., S.A. French, J.M. Oakes, M.T. Story, R.W. Jeffery, and S.A. Rydell. 2008. "Effects of Calorie Labelling and Value Size Pricing on Fast Food Meal Choices: Results from an Experimental Trial." International Journal of Behavioral Nutrition and Physical Activity (63)5: 1-13.

Hellmich, N. 2013. "U.S. obesity rate levels off, but still an epidemic." USA Today. Available at http://www.usatoday.com/story/news/nation/2013/10/17/obesity-rate-levels-off/ 2895759 (accessed 10 April 2014). 
Ikeda, S., M.I. Kang, and F. Ohtake. 2010. "Hyperbolic Discounting, the Sign Effect, and the Body Mass Index." Journal of Health Economics 29(2): 268-284.

Kahneman, D., and A. Tversky. 1979. "Prospect Theory: An Analysis of Decision Under Risk." Econometrica 47(2): 263-291.

Keneally, M. 2012. 'Mom, why am I fat?' Controversy over shock anti-obesity ads featuring overweight children." Daily Mail. Available at http://www.dailymail.co.uk/news/article2081328 (accessed 10 April 2014).

Komlos, J., P.K. Smith, and B. Bogin. 2004. "Obesity and the Rate of Time Preference: Is There a Connection?" Journal of Biosocial Science 36(2): 209-219.

Kuchler, F., A. Tegene, and J.M. Harris. 2005. "Taxing Snacking Foods: Manipulating Diet Quality or Financing Information Programs?" Review of Agricultural Economics 27(1): 4-20.

Laibson, D. 2001. "A Cue-Theory of Consumption." Quarterly Journal of Economics 116(1): 81-119.

Levin, I.P., S.L. Schneider, and G.J. Gaeth. 1998. "All Frames Are Created Equal: A Typology and Critical Analysis of Framing Effect." Organizational Behavior and Human Decision Process 76(2): 149-188.

Levitt, S.D., and J.A. List. 2007. "Viewpoint: On the Generalizability of Lab Behavior to the Field." Canadian Journal of Economics 40(2): 347-370.

Liaukonyte, J., B.J. Rickard, H.M. Kaiser, A.M. Okrent, and R.J. Richards. 2012. "Economic and Health Effects of Fruit and Vegetable Advertising: Evidence From Lab Experiments." Food Policy 37(5): 543-553.

Liu, P.J., J. Wisdom, C.A. Roberto, L.J. Liu, and P.A. Ubel. 2014. “Using Behavioral Economics to Design More Effective Food Policies to Address Obesity." Applied Economics Perspective and Policy 36(1): 1-24.

Loewenstein, G., J. Downs, and J. Wisdom. 2009. "Strategies for Promoting Healthier Food Choices." American Economic Review 99(2): 159-164.

McClure, S., D. Laibson, G. Loewenstein, and J. Cohen. 2007. "Time Discounting for Primary Rewards." Journal of Neuroscience 27(21): 5796-5804.

O'Donoghue, T., and M. Rabin. 1999. "Doing It Now or Later." American Economic Review 89 (1): 103-124.

Peeters, G., and J. Czapinski. 1990. "Positive-Negative Asymmetry in Evaluations: The Distinction Between Affective and Informational Negativity Effects." European Review of Social Psychology 1(1): 33-60.

Pollard, C.M., M.R. Miller, A.M. Daley, et al. 2008. "Increasing Fruit and Vegetable Consumption: Success of the Western Australian Go for $2 \& 5$ Campaign." Public Healthy Nutrition 11(3): 314-320.

Powell, L.M., and F.J. Chaloupka. 2009. "Food Prices and Obesity: Evidence and Policy Implication for Taxed and Subsidies." Milbank Quarterly 87(1): 229-257.

Rickard, B.J., J. Liaukonyte, H.M. Kaiser, and T.J. Richards. 2011. "Consumer Response to Commodity-Specific and Broad-Based Promotion Programs for Fruits and Vegetables." American Journal of Agricultural Economics 93(5): 1312-1327.

Roberto, C.A., P.D. Larsen, H. Agnew, J. Baik, and K.D. Brownell. 2010. "Evaluating the Impact of Menu Labeling on Food Choices and Intake." American Journal of Public Health 100(2): 312-318.

Roland, M.L. 1990. "Self-Reported Weight and Height." American Journal of Clinical Nutrition 152(6): 1125-1133.

Ruiter, R.A., C. Abraham, and G. Kock. 2001. "Scary Warnings and Rational Precautions: A Review of the Psychology of Fear Appeal." Psychology and Healthy 16(6): 613-630.

Rusmevichientong, P., N.A. Streletskaya, W. Amatyakul, and H.M. Kaiser. 2014. "The Impact of Food Advertisements on Changing Eating Behaviors: An Experimental Study." Food Policy 44: 59-67.

Schvey, N.A., R.M. Puhl, and K.D. Brownell. 2011. "The Impact of Weight Stigma on Caloric Consumption." Obesity 19(10): 1957-1962.

Schwartz, J., J. Riis, B. Elbel, and D. Ariely. 2012. "Inviting Consumers to Downsize Food Portions Significantly Reduces Calorie Consumption.” Health Affairs 31(2): 399-407. 
Spencer, E., P.N. Appleby, G.K. Davey, and T.J. Key. 2007. "Validity of Self-Reported Height and Weight in 4808 EPIC-Oxford Participants." Public Health Nutrition 5(4): 561-565.

Streletskaya, A.N., P. Rusmevichientong, W. Amatyakul, and H.M. Kaiser. 2013. "Taxes, Subsidies, and Advertising Efficacy in Changing Eating Behavior: An Experimental Study." Applied Economics Perspective and Policy 36(1): 146-174.

Wansink, B. 2006. Mindless Eating: Why We Eat More Than We Think. Random House LLC, New York.

Zhang, L., and I. Rashad. 2008. “Obesity and Time Preference: The Health Consequences of Discounting the Future." Journal of Biosocial Science 40(1): 97-113.

\section{APPENDIX}

\section{Table A1. TV Excerpts and Advertisements Used in the Experiment}

\begin{tabular}{|c|c|c|}
\hline Used in & Name & Source \\
\hline All treatments & Rube Goldberg Machine & Portlandia, Season3, Episode 8 \\
\hline All treatments & 2 Girls 2 Shirts & Portlandia, Season2, Episode 6 \\
\hline All treatments & Books on Parenting & Portlandia, Season3, Episode 9 \\
\hline All treatments & Wilson Light Bulbs & Portlandia, Season3, Episode 3 \\
\hline $\begin{array}{l}\text { Healthy eating } \\
\text { treatment }\end{array}$ & $\begin{array}{l}\text { Challenge Someone to Live } \\
\text { Well }\end{array}$ & Live Well Colorado \\
\hline $\begin{array}{l}\text { Healthy eating } \\
\text { treatment }\end{array}$ & $\begin{array}{l}\text { Growing a Healthy Child } \\
\text { (2007) }\end{array}$ & Arizona Nutrition Network \\
\hline $\begin{array}{l}\text { Healthy eating } \\
\text { treatment }\end{array}$ & $\begin{array}{l}\text { Growing a Healthy Child } \\
\text { (2008) }\end{array}$ & Arizona Nutrition Network \\
\hline $\begin{array}{l}\text { Healthy eating } \\
\text { treatment }\end{array}$ & Wouldn't It Be Nice & Independent producer \\
\hline $\begin{array}{l}\text { Healthy eating } \\
\text { treatment }\end{array}$ & Make a Clean Start & Terry Walters \\
\hline $\begin{array}{l}\text { Healthy eating } \\
\text { treatment }\end{array}$ & $\begin{array}{l}\text { Eat } 2 \text { Fruit }+2 \text { Veggies } \\
\text { Every Day }\end{array}$ & $\begin{array}{l}\text { Health Promotion Board, } \\
\text { Singapore }\end{array}$ \\
\hline $\begin{array}{l}\text { Anti-obesity } \\
\text { treatment }\end{array}$ & This is Joe & $\mathrm{CDC}$ \\
\hline $\begin{array}{l}\text { Anti-obesity } \\
\text { treatment }\end{array}$ & Be Food Smart & Change4 Life England \\
\hline $\begin{array}{l}\text { Anti-obesity } \\
\text { treatment }\end{array}$ & Eating Out & $\begin{array}{l}\text { Blue Cross and Blue Shield } \\
\text { Minnesota }\end{array}$ \\
\hline $\begin{array}{l}\text { Anti-obesity } \\
\text { treatment }\end{array}$ & Don't Drink Yourself Fat & NYC Department of Health \\
\hline $\begin{array}{l}\text { Anti-obesity } \\
\text { treatment }\end{array}$ & Man Eating Sugar & NYC Department of Healthy \\
\hline $\begin{array}{l}\text { Anti-obesity } \\
\text { treatment }\end{array}$ & Stop the Cycle & Strong4 Life Atlanta \\
\hline
\end{tabular}

Complete media clips used in the experiment for control and treatment groups can be found via the following URL: http://tinyurl.com/ovt6xgg 


\section{Table A2. Survey Questions}

\section{\# Question}

1. What is your age?

2. What is your gender?

3. What is your race?

4. What is your weight?

5. What is your height?

6. I feel_healthy _unhealthy _not sure about my health condition (mark one that applies)

7. What is your household income level? _ less than $\$ 40,000 \_\$ 40,000-\$ 80,000 \_\$ 80,000-\$ 120,000 \_\$ 120,000-\$ 160,000 \_$over $\$ 160,000$

8. What is the highest education level that you have achieved? _ High School_ some college but no degree __ Associates Degree _ College Degree __ Master's Degree _ Doctoral

9. Are you married or living with someone in a long term relationship? Yes No

10. Do you have children under 18 years old living at home? Yes

No

11. Are you a Vegetarian or Vegan? Yes No

12. How many meals per week do you purchase from a restaurant or a cafeteria?

13. Are you the primary food shopper in your family? Yes No

14. How likely are you to purchase a snack food that you have not tried before? Not at all likely Not very likely Somewhat likely _Likely Very likely

15. On average, how frequently do you eat snack foods? (mark one)Once a day, twice a day, three times a day, more than 3 times a day, less than once a week

16. How much did you like the TV show? Using a scale from 1 (dislike it very much) to 10 (like it very much) _

17. How much did you like the TV show? Using a scale from 1 (dislike it very much) to 10 (like it very much) 


\section{Table A3. Recruiting Announcement}

\begin{tabular}{ll}
\hline $\begin{array}{l}\text { Study Name } \\
\text { Abstract }\end{array}$ & $\begin{array}{l}\text { Snack Food Study (No Students) } \\
\text { Description }\end{array}$ \\
$\begin{array}{l}\text { During the study, you will be asked to submit bids for a series of snack food items and there is a possibility of } \\
\text { purchasing up to one of the auctioned items. You will also watch some videos, complete a survey about yourself, } \\
\text { and have your height and weight measured. }\end{array}$ \\
$\begin{array}{l}\text { Eligibility } \\
\text { Requirements } \\
\text { Duration }\end{array}$ & 35 minutes \\
\hline
\end{tabular}


Table A4. Individual Product Bids and Product Fixed Effects Estimates (i) Average Bids and Standard Deviations by Auction Item Before Advertising

\begin{tabular}{|c|c|c|c|c|c|c|}
\hline \multirow[b]{2}{*}{ Products } & \multicolumn{2}{|c|}{ Control Group } & \multicolumn{2}{|c|}{ Anti-Obesity Advertising } & \multicolumn{2}{|c|}{ Healthy Eating Advertising } \\
\hline & Overweight & Normal-Weight & Overweight & Normal-Weight & Overweight & Normal-Weight \\
\hline Apple & $\begin{array}{c}0.446 \\
(0.266)\end{array}$ & $\begin{array}{c}0.585 \\
(0.761)\end{array}$ & $\begin{array}{c}0.521 \\
(0.360)\end{array}$ & $\begin{array}{c}0.462 \\
(0.389)\end{array}$ & $\begin{array}{c}0.567 \\
(0.384)\end{array}$ & $\begin{array}{c}0.51 \\
(0.245)\end{array}$ \\
\hline Orange & $\begin{array}{c}0.47 \\
(0.298)\end{array}$ & $\begin{array}{c}0.626 \\
(0.775)\end{array}$ & $\begin{array}{c}0.557 \\
(0.302)\end{array}$ & $\begin{array}{c}0.469 \\
(0.365)\end{array}$ & $\begin{array}{c}0.495 \\
(0.363)\end{array}$ & $\begin{array}{c}0.487 \\
(0.279)\end{array}$ \\
\hline Water & $\begin{array}{c}0.948 \\
(0.457)\end{array}$ & $\begin{array}{c}0.83 \\
(0.830)\end{array}$ & $\begin{array}{l}0.9 \\
(0.456)\end{array}$ & $\begin{array}{c}0.768 \\
(0.551)\end{array}$ & $\begin{array}{c}0.945 \\
(0.868)\end{array}$ & $\begin{array}{c}0.905 \\
(0.517)\end{array}$ \\
\hline Cola & $\begin{array}{c}0.986 \\
(0.551)\end{array}$ & $\begin{array}{c}0.589 \\
(0.660)\end{array}$ & $\begin{array}{c}0.779 \\
(0.624)\end{array}$ & $\begin{array}{c}0.646 \\
(0.783)\end{array}$ & $\begin{array}{c}1.112 \\
(0.913)\end{array}$ & $\begin{array}{c}0.838 \\
(0.737)\end{array}$ \\
\hline Chips & $\begin{array}{c}0.745 \\
(0.375)\end{array}$ & $\begin{array}{c}0.634 \\
(0.476)\end{array}$ & $\begin{array}{c}0.721 \\
(0.458)\end{array}$ & $\begin{array}{c}0.686 \\
(0.651)\end{array}$ & $\begin{array}{c}0.936 \\
(0.436)\end{array}$ & $\begin{array}{c}0.761 \\
(0.514)\end{array}$ \\
\hline Cookie & $\begin{array}{c}0.607 \\
(0.401)\end{array}$ & $\begin{array}{c}0.587 \\
(0.648)\end{array}$ & $\begin{array}{c}0.635 \\
(0.474)\end{array}$ & $\begin{array}{c}0.567 \\
(0.496)\end{array}$ & $\begin{array}{c}0.743 \\
(0.425)\end{array}$ & $\begin{array}{c}0.667 \\
(0.521)\end{array}$ \\
\hline Candy Bar & $\begin{array}{c}0.745 \\
(0.375)\end{array}$ & $\begin{array}{c}0.634 \\
(0.476)\end{array}$ & $\begin{array}{c}0.721 \\
(0.457)\end{array}$ & $\begin{array}{c}0.686 \\
(0.651)\end{array}$ & $\begin{array}{c}0.937 \\
(0.436)\end{array}$ & $\begin{array}{c}0.761 \\
(0.512)\end{array}$ \\
\hline
\end{tabular}


(ii) Average Bids and Standard Deviations by Auction Item After Advertising

\begin{tabular}{|c|c|c|c|c|c|c|}
\hline \multirow[b]{2}{*}{ Products } & \multicolumn{2}{|c|}{ Control Group } & \multicolumn{2}{|c|}{ Anti-Obesity Advertising } & \multicolumn{2}{|c|}{ Healthy Eating Advertising } \\
\hline & Overweight & Normal-Weight & Overweight & Normal-Weight & Overweight & Normal-Weight \\
\hline Apple & $\begin{array}{c}0.457 \\
(0.274)\end{array}$ & $\begin{array}{c}0.578 \\
(0.770)\end{array}$ & $\begin{array}{c}0.681 \\
(0.499)\end{array}$ & $\begin{array}{c}0.539 \\
(0.408)\end{array}$ & $\begin{array}{c}0.745 \\
(0.572)\end{array}$ & $\begin{array}{c}0.584 \\
(0.282)\end{array}$ \\
\hline Orange & $\begin{array}{c}0.470 \\
(0.304)\end{array}$ & $\begin{array}{c}0.598 \\
(0.787)\end{array}$ & $\begin{array}{c}0.744 \\
(0.557)\end{array}$ & $\begin{array}{c}0.530 \\
(0.426)\end{array}$ & $\begin{array}{c}0.727 \\
(0.515)\end{array}$ & $\begin{array}{c}0.603 \\
(0.389)\end{array}$ \\
\hline Water & $\begin{array}{c}0.952 \\
(0.462)\end{array}$ & $\begin{array}{c}0.792 \\
(0.858)\end{array}$ & $\begin{array}{c}0.952 \\
(0.462)\end{array}$ & $\begin{array}{c}0.816 \\
(0.557)\end{array}$ & $\begin{array}{c}0.935 \\
(0.599)\end{array}$ & $\begin{array}{c}0.972 \\
(0.551)\end{array}$ \\
\hline Cola & $\begin{array}{c}1.000 \\
(0.542)\end{array}$ & $\begin{array}{c}064 \\
(0.793)\end{array}$ & $\begin{array}{c}0.256 \\
(0.295)\end{array}$ & $\begin{array}{c}0.244 \\
(0.499)\end{array}$ & $\begin{array}{c}0.613 \\
(0.573)\end{array}$ & $\begin{array}{c}0.662 \\
(0.632)\end{array}$ \\
\hline Chips & $\begin{array}{c}0.733 \\
(0.359)\end{array}$ & $\begin{array}{c}0.675 \\
(0.512)\end{array}$ & $\begin{array}{c}0.458 \\
(0.364)\end{array}$ & $\begin{array}{c}0.651 \\
(0.568)\end{array}$ & $\begin{array}{c}0.836 \\
(0.436)\end{array}$ & $\begin{array}{c}0.761 \\
(0.514)\end{array}$ \\
\hline Cookie & $\begin{array}{c}0.607 \\
(0.401)\end{array}$ & $\begin{array}{c}0.587 \\
(0.648)\end{array}$ & $\begin{array}{c}0.336 \\
(0.340)\end{array}$ & $\begin{array}{c}0.478 \\
(0.484)\end{array}$ & $\begin{array}{c}0.678 \\
(0.434)\end{array}$ & $\begin{array}{c}0.567 \\
(0.454)\end{array}$ \\
\hline Candy bar & $\begin{array}{c}0.652 \\
(0.397)\end{array}$ & $\begin{array}{c}0.565 \\
(0.567)\end{array}$ & $\begin{array}{c}0.368 \\
(0.368)\end{array}$ & $\begin{array}{c}0.339 \\
(0.356)\end{array}$ & $\begin{array}{c}0.537 \\
(0.406)\end{array}$ & $\begin{array}{c}0.509 \\
(0.357)\end{array}$ \\
\hline
\end{tabular}


(iii) Estimates of Item Fixed Effects (see Table 3).

\begin{tabular}{|c|c|c|c|c|c|c|}
\hline & \multicolumn{2}{|c|}{$\begin{array}{c}\text { (1) BMI: Normal Weight vs. } \\
\text { Overweight }\end{array}$} & \multicolumn{2}{|c|}{ (2) BMI: by 10 Percentile Bins } & \multicolumn{2}{|c|}{ (3) BMI: by Continuous BMI } \\
\hline & Healthy Items & Unhealthy Items & Healthy Items & Unhealthy Items & Healthy Items & Unhealthy Items \\
\hline \multirow[t]{2}{*}{ Constant } & 0.019 & $-0.070^{* *}$ & 0.019 & $-0.070^{* *}$ & 0.019 & $-0.071 * *$ \\
\hline & $(0.017)$ & $(0.032)$ & $(0.017)$ & $(0.032)$ & $(0.017)$ & $(0.032)$ \\
\hline \multirow[t]{2}{*}{ Cookie } & & $0.147^{* * *}$ & & $0.147^{* * *}$ & & $0.148^{* * *}$ \\
\hline & & $(0.043)$ & & $(0.043)$ & & $(0.043)$ \\
\hline \multirow[t]{2}{*}{ Chips } & & $0.095^{* *}$ & & $0.095^{* *}$ & & $0.098^{* *}$ \\
\hline & & $(0.040)$ & & $(0.040)$ & & $(0.040)$ \\
\hline \multirow[t]{2}{*}{ Candy } & & $0.073^{*}$ & & $0.073^{*}$ & & $0.075^{*}$ \\
\hline & & $(0.037)$ & & $(0.037)$ & & $(0.037)$ \\
\hline \multirow[t]{2}{*}{ Water } & $-0.062^{* *}$ & & $-0.062 * *$ & & $-0.062^{* *}$ & \\
\hline & $(0.030)$ & & $(0.030)$ & & $(0.030)$ & \\
\hline \multirow[t]{2}{*}{ Apple } & -0.015 & & -0.015 & & -0.016 & \\
\hline & $(0.017)$ & & $(0.017)$ & & $(0.017)$ & \\
\hline R2 & 0.057 & 0.154 & 0.091 & 0.157 & 0.103 & 0.150 \\
\hline Obs. & 548 & 731 & 548 & 731 & 542 & 723 \\
\hline
\end{tabular}

Note: ${ }^{* * *} \mathrm{p}<0.0 \mathrm{l},{ }^{* *} \mathrm{p}<0.05, * \mathrm{p}<0.1$; Robust clustered standard errors; item fixed effects included in all of the specifications. Specification (1) BMI is an indicator variable for overweight individuals (BMI > 25): Specification (2) BMI takes value of 1 to 10 by percentile bins (see Figure 1); Specification (3): BMI is a continuous variable corresponding to an actual measured BMI with outlier observations (BMI in the 99th percentile and above) excluded. Cola and orange are excluded dummies for unhealthy and healthy item specifications, respectively. 